\title{
Comparative Study of Static and Interactive VisualizationApproaches
}

\author{
Kirti Nilesh Mahajan \\ Institute of Management and Entrepreneurship Development (IMED), \\ BharatiVidyapeeth Deemed University, Pune, Maharashtra, India \\ kirtimahajan75@gmail.com \\ Leena Ajay Gokhale \\ Institute of Management and Entrepreneurship Development (IMED), \\ BharatiVidyapeeth Deemed University, Pune, Maharashtra, India \\ leenagokhale9999@gmail.com
}

\begin{abstract}
Visualizations are envisioned for presenting the data in the graphical format for the purpose of communicating different data stories in the uniform format, making it easily understandable to the viewers, irrespective of the languages known to them. Several visualization approaches and numerous tools supporting those approaches are undertaken by the organizations to fulfil their visualization requirements. The two key approaches of visualizations are Static visualization and Interactive visualization. The key purpose of both theseapproaches is identical, that is to communicate the data graphically, based on data stories. However, there is vast difference between these two approaches, in terms of several factors, such as input techniques, processing methods and output ways. While the graphic of Static visualization communicates a single data story, the Interactive visualization image allows extracting multiple views of the data storieswhich is subject to change as it is based on various inputs via mouse or keyboard. While static visualization has author driven approach, interactive visualization has reader driven approach, creating it highly interactive. The approach may be selected depending upon the purpose of communication, the target audience and availability of the visualization tool. The purpose of this paper is to present the comparison between Static and Interactive approaches of visualization. In this paper, we also describe overview of the factors influencing the selection of visualizationapproach between Static and Interactive along with the key phases involved before and after visualization.
\end{abstract}

Keywords - Visualization, Visualization Approaches, Static Visualization, Interactive Visualization, Event Driven Programming, Graphical User Interface (GUI), Big Data.

\section{INTRODUCTION}

Data visualization is becomingprogressively key element of data analytics in the era of big data. Data visualization certainly plays a vital role in presenting the data graphically and stating clear understanding of the data. Visualization is avoyage from unknown to known, where hidden insights can be discovered.Visualization also aims to improve the accuracy and appearance of the information discovered. Due to the advancement in the digital technologies, numerous ways of colleting, storing, processing and visualizing the data are in practice. As a result, the size and complexity of the data are growing at a rapid speed. Features of Big data integrate volume, velocity, variety and veracity, together making the data more complex and difficult to analyze. [2] These features together states that the data is too large and complex to visualize using conventional approaches.Meaningful information need to be extracted from this huge data in order to take numerous data driven business decisions. Precise hardware and software requirements need to be fulfilled for accomplishing the benefits of visualization. Several visualization approaches are in practice today. Most common visualization approaches are Static Visualization and Interactive Visualization. A static visualization approachprovides a static graphicwhich is fixed and does not allow the user to interact with data and to participate in the visualization process.An interactive visualizationconveys an interactive graphic that allows the user to participate in the visualization process and to edit the graphic by giving further inputs. Interactive visualization approach offers numerous opportunities of exploring the data in the big data. Selecting the approach between these two approaches is a challenge for the users. Various factors influence on the selection of the visualization approach. Before selecting the approach of visualization,organizations needto define the visualization strategies after considering various factors. 


\section{VISUALIZATION}

Visualization of the data is converting the qualitative and quantitative data in the graphical format instead of presenting the data in text and numbers. [5]In addition to anenhanced way to present the data, visualization also offer an effective way of ganing knowledge. [7] Transforming the data in the image formatwith the help of precise software is the need of modern business. As the images are self-explaianatory, it may not require further explanation, which reduces the time and efforts to explain the meaning of the information. [3] This graphically presented information is more appealing and has the skill to display the large and complex data in more understandable format.Significance of visualization is growing as this technique allows the user to view the complex information graphically. This is a compelling way of communicating the information rather than presenting it in the form of tables showing text and numbers. Visualization helps to interpret the information quickly. There is a wide scope for applications of visualizations in business decisions such as predicting market developments, identification of the problem, analysing customer purchase trends, accurate data analysis, exploring hidden patterns etc. [4]Visualization is a powerful tool for discovering the hidden insights. [9]

\section{VISUALIZATION APPROACHES}

Current technologies allow the user to look at the data differently. The same data may be presented exclusively by considering different approaches. The conventional approaches may not be always suitable for modern type of data. Since the data formats are changing, there is a need to understand the visualization requirements differently. Both, static and interactive visualization approachesare built in different environments, which integrate different components. Both these approaches have same purpose of communication, based on certain data stories. However, both, static and interactive visualization approaches have their own features, merits and demerits.

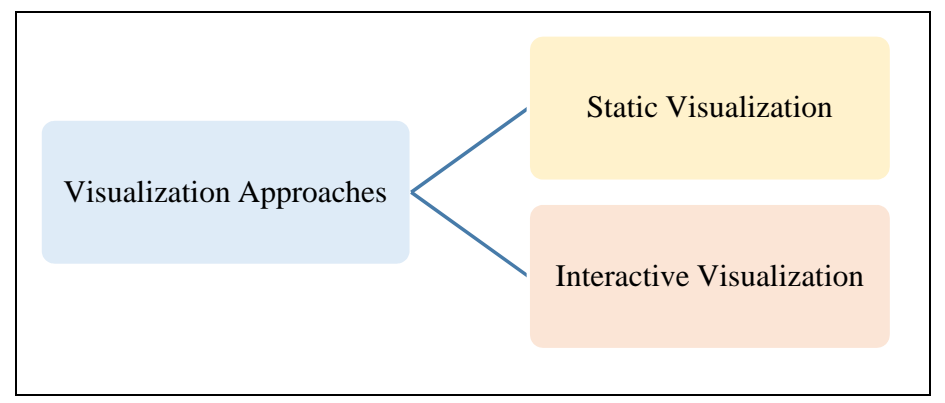

Figure 1. Visualization Approaches

\section{A. Static Visualization}

A Static visualization holds an author driven approach which does not allow the readers to interact with the data. [6] The process of static visualization has a precise sequence of steps that are followed strictly. Graphical Static visualizations focus on a specific data story, giving a single view of the selected data story.The scope of this approach is limited and hence is recommended for small sized data. This approach does not convey new insights. [8] The static graphical object is displayed on the viewport in the format of an image. Static images are visual images that do not move and do not allow direct communication between the data and the user. This image commonly is in a bitmap format. Examples of static images include charts, posters, photographs etc.An advantage of this feature is that the privacy and security of the data is on higher side. Static images are flat images such as Line Chart, Pie Chart etc. [5] Mostly, static images are combination of visual elements and words. Static visualizers are functioning with rigid charts and graphics that prevent creative data exploration. Static visualizations are executed only once. The visualization designer has to make sure that all the key points are visible in the graphic since further mouse or keyboard events are not allowed. This static graphic displays the information which is not subject to change at the viewer end. However, the size of the image may be increased or decreased by changing the dimensions.

\section{B. Interactive Visualization}

An Interactive visualization has a reader driven approach where the role of the reader is not only to view the data but to interact with the data as well. [6] This approach conveys new insights. [8] Interactive visualization allows the user to explore the data, going beyond just viewing the graphical information displayed. [7] Since the reader is allowed to give inputs several times, no precise sequence of steps is followed during the visualization process. Graphical Interactive visualizations are demand driven and event-driven operated on the basis of mouse and keyboard event handling, having continuous input. This approach allows the user to access different parts of the data and dig the data deeply to get the desired results by clicking on the image or some specific part of the image. [5] The scope of this approach is wider as this approach helps in discovery of hidden insights. This feature reduces the privacy and security of the data. The challenge is to maintain the security of the graphic displayed as well since the graphic gets changed with each event. Often, the outputs are event driven as these are based on the 
inputs given by the viewer by mouse clicks or keyboard strikes. However, in order to succeed, the user must possess the combination of skills such as technical knowledge of the tool, innovative new ideas plus skill of interacting with the huge data, with the help of visualization tool. The concept of interactive visualization takes the user beyond the limitations of conventional charts and graphs.Interactive visualization applications are built on the foundation of event driven programming. Events are numerous activities that happen during a program such as mouse movement, mouse clicks or key strokes. [10] In these applications, the program code is executed when a particular event is fired. It means that the statements in the program are executed when an event calls the precise part of the program that is assigned to that event. Example: A text box may have an event such as click event or mouse over event. [10]

1) Mouse Events:These events are based on certain input given with the help of mouse. [10] The precise set of code is executed when a particular mouse event is fired. However, the approaches of giving inputs for each event is different.

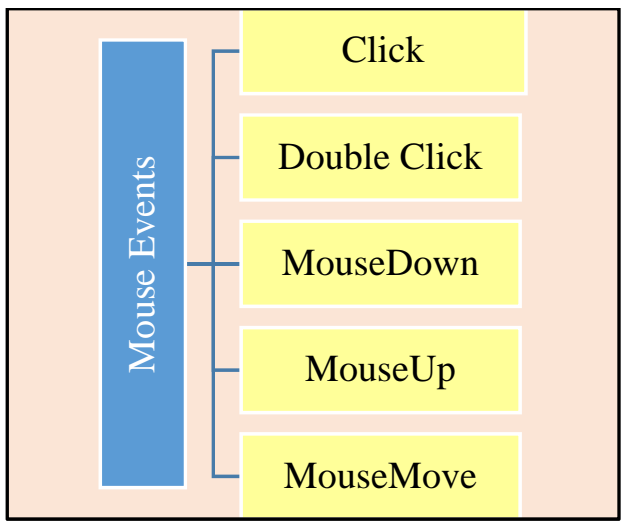

Figure 2. Example of a Mouse Events

2) Keyboard Events: These events are based on certain input given with the help of key strokes. Mostly, a particular key has to be pressed in order to execute the particular code. [10] Two vital keyboard events are keypress and keyrelease.

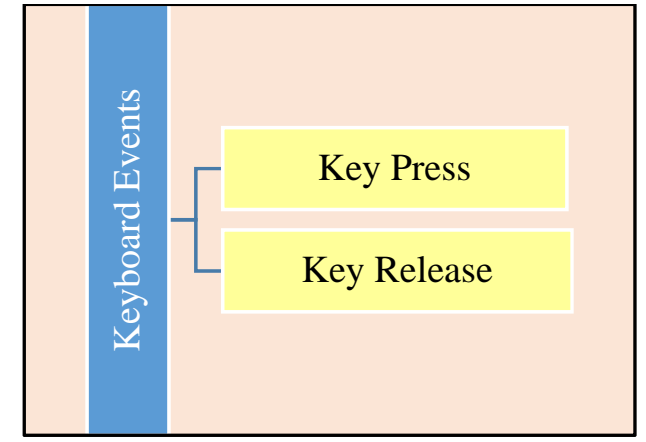

Figure 3. Example of a Keyboard Events

TABLE I. COMPARISON OF STATIC AND INTERACTIVE VISUALIZATION APPROACHES

\begin{tabular}{|c|c|c|}
\hline \multirow{2}{*}{$\begin{array}{l}\text { Visualization } \\
\text { Approaches }\end{array}$} & \multicolumn{2}{|c|}{ Comparison of Static and Interactive Visualization } \\
\hline & Static Visualization & Interactive Visualization \\
\hline Concept: & \begin{tabular}{|ll} 
1) & Author driven approach \\
2) & Read only \\
3) & Allows Data Presentation \\
4) & Executed Only Once \\
5) & No Interactivity \\
6) & Less Flexible \\
7) & Rigid Chart Style \\
8) & Linear Approach \\
9) & Components are data, code and \\
& graphic \\
10) & Do not convey new insights
\end{tabular} & $\begin{array}{l}\text { 1) Reader driven approach } \\
\text { 2) Read and Demand } \\
\text { 3) Allows Data Exploration } \\
\text { 4) Has further Inputs and Outputs } \\
\text { 5) Highly Interactive } \\
\text { 6) More Flexible } \\
\text { 7) Event Driven Style } \\
\text { 8) Allows Graphical User Interface } \\
\text { (GUI) } \\
\text { 9) Components are data, code, } \\
\text { events and graphic } \\
\text { 10) Convey new insights }\end{array}$ \\
\hline
\end{tabular}




\begin{tabular}{|c|c|c|c|c|}
\hline Tool: & 1) & MS Excel & 1) & Tableau \\
\hline Useful for: & & $\begin{array}{l}\text { Business Presentations } \\
\text { Business Trainings }\end{array}$ & 1) & $\begin{array}{l}\text { Exploring Data Patterns } \\
\text { Data Discovery }\end{array}$ \\
\hline Components: & $\begin{array}{l}\text { 1) } \\
\text { 2) } \\
\text { 3) } \\
\text { 4) } \\
\text { 5) }\end{array}$ & $\begin{array}{l}\text { Computer Hardware } \\
\text { Visualization Software } \\
\text { Data } \\
\text { Code without events } \\
\text { Graphical non-interactive static } \\
\text { output }\end{array}$ & $\begin{array}{l}\text { 1) } \\
\text { 2) } \\
\text { 3) } \\
\text { 4) } \\
\text { 5) }\end{array}$ & $\begin{array}{l}\text { Computer Hardware } \\
\text { Visualization Software } \\
\text { Data } \\
\text { Code with events } \\
\text { Graphical interactive output }\end{array}$ \\
\hline $\begin{array}{l}\text { Data to be } \\
\text { visualized: Input: }\end{array}$ & $\begin{array}{l}\text { 1) } \\
\text { 2) } \\
\text { 3) }\end{array}$ & $\begin{array}{l}\text { Quantity of data represented is } \\
\text { less } \\
\text { Data remains fixed } \\
\text { A specific data story can be } \\
\text { visualized }\end{array}$ & $\begin{array}{l}\text { 2) } \\
\text { 3) }\end{array}$ & $\begin{array}{l}\text { Quantity of data represented is } \\
\text { more } \\
\text { Data gets changed } \\
\text { Larger data sets having more } \\
\text { complex stories can be visualized }\end{array}$ \\
\hline Process on Data: & $\begin{array}{l}\text { 1) } \\
\text { 2) }\end{array}$ & $\begin{array}{l}\text { Information on one data story can } \\
\text { be processed only once } \\
\text { Requires less time to process the } \\
\text { data as limited data is processed }\end{array}$ & 2) & $\begin{array}{l}\text { Data is processed each time user } \\
\text { gives an input } \\
\text { Needs more time to process the } \\
\text { data as different data is processed } \\
\text { for each event }\end{array}$ \\
\hline $\begin{array}{l}\text { Information } \\
\text { Displayed: } \\
\text { Output: }\end{array}$ & $\begin{array}{l}\text { 1) } \\
\text { 2) } \\
\text { 3) } \\
\text { 4) }\end{array}$ & $\begin{array}{l}\text { Single view of the data } \\
\text { Single page display } \\
\text { Output is viewed as simple plain } \\
\text { image } \\
\text { Mostly, it is a bitmap image } \\
\text { format }\end{array}$ & $\begin{array}{l}\text { 1) } \\
\text { 2) } \\
\text { 3) } \\
\text { 4) }\end{array}$ & $\begin{array}{l}\text { Multiple views of the data } \\
\text { Multiple pages display } \\
\text { Output is seen as application } \\
\text { Mostly, it is a SVG format used } \\
\text { for displaying a vector image } \\
\text { format }\end{array}$ \\
\hline Role of the User: & $\begin{array}{l}\text { 1) } \\
\text { 2) } \\
3) \\
\text { 4) } \\
\text { 5) }\end{array}$ & $\begin{array}{l}\text { Users do not get an opportunity to } \\
\text { explore the data } \\
\text { Multiple users can view the result } \\
\text { User is only the viewer of the } \\
\text { result as user does not participate } \\
\text { in the visualization process } \\
\text { More suitable for target audience } \\
\text { who are digitally inclined } \\
\text { Users depend upon the tool to get } \\
\text { the required data }\end{array}$ & 2) & $\begin{array}{l}\text { Users get many opportunities to } \\
\text { explore the data through mouse } \\
\text { and keyboard inputs } \\
\text { Only one user may give an input } \\
\text { at a time } \\
\text { Users are the part of the } \\
\text { visualization process since further } \\
\text { results depend upon his inputs } \\
\text { Effective for techno-savvy users } \\
\text { Users are more self-sufficient to } \\
\text { find the required data }\end{array}$ \\
\hline Merits: & $\begin{array}{l}\text { 1) } \\
\text { 2) } \\
\text { 3) } \\
\text { 4) } \\
5) \\
\text { 6) } \\
\text { 7) }\end{array}$ & $\begin{array}{l}\text { Static visualization can function } \\
\text { with basic tools and technology } \\
\text { Specific training to the users is } \\
\text { not required } \\
\text { Less expensive } \\
\text { Simple to use and understand } \\
\text { Single graphical output is easy to } \\
\text { save for future reference } \\
\text { It is fast } \\
\text { It displays identical graphic to } \\
\text { each user }\end{array}$ & $\begin{array}{l}\text { 5) } \\
6) \\
7 \text { ) }\end{array}$ & $\begin{array}{l}\text { Require specific tool that support } \\
\text { interactions during visualization } \\
\text { Helps to determine hidden } \\
\text { insights } \\
\text { High interactive } \\
\text { Multiple views because of } \\
\text { ongoing inputs } \\
\text { More Effective } \\
\text { More Creative } \\
\text { Provides the solution for larger } \\
\text { data sets with complex data } \\
\text { Wider scope } \\
\text { More details can be determined }\end{array}$ \\
\hline Demerits: & $\begin{array}{l}\text { 1) } \\
\text { 2) } \\
\text { 3) } \\
\text { 4) } \\
\text { 5) }\end{array}$ & $\begin{array}{l}\text { Static visualizers are functioning } \\
\text { with rigid charts and graphics that } \\
\text { prevent creative data exploration } \\
\text { No interactivity } \\
\text { Single view } \\
\text { Less effective } \\
\text { Static visualization provides the } \\
\text { solution for very limited data }\end{array}$ & $\begin{array}{l}\text { 4) } \\
5)\end{array}$ & $\begin{array}{l}\text { Require specific tool that support } \\
\text { interactions during visualization } \\
\text { This leads to precise hardware } \\
\text { and software requirements } \\
\text { More training to the users is } \\
\text { required } \\
\text { No specific sequence of results } \\
\text { More expensive }\end{array}$ \\
\hline
\end{tabular}




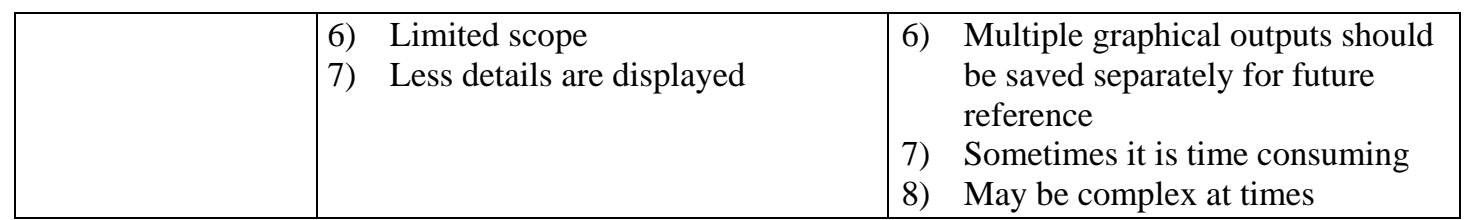

\section{FACTORS INFLUENCING THE SELECTION OF VISUALIZATION APPROACH}

Each organization has different requirements of visualization. The selection of the visualization approach may be completed after determining the factors such as availability of the required hardware and software, purpose of the visualization, target audience, whether the user is allowed to participate in the process of visualization or he should play the role of the viewer only. [1] The hardware and software requirements may be different for each of these approaches. Hence the availability of the same at both the ends, visualization designer and the viewer should be taken into consideration. Since all the visualization tools may not support interaction, the tool must be chosen carefully. Further, technical training to the viewers may be required in case of interactive visualization approach, increasing the financial cost of the same.

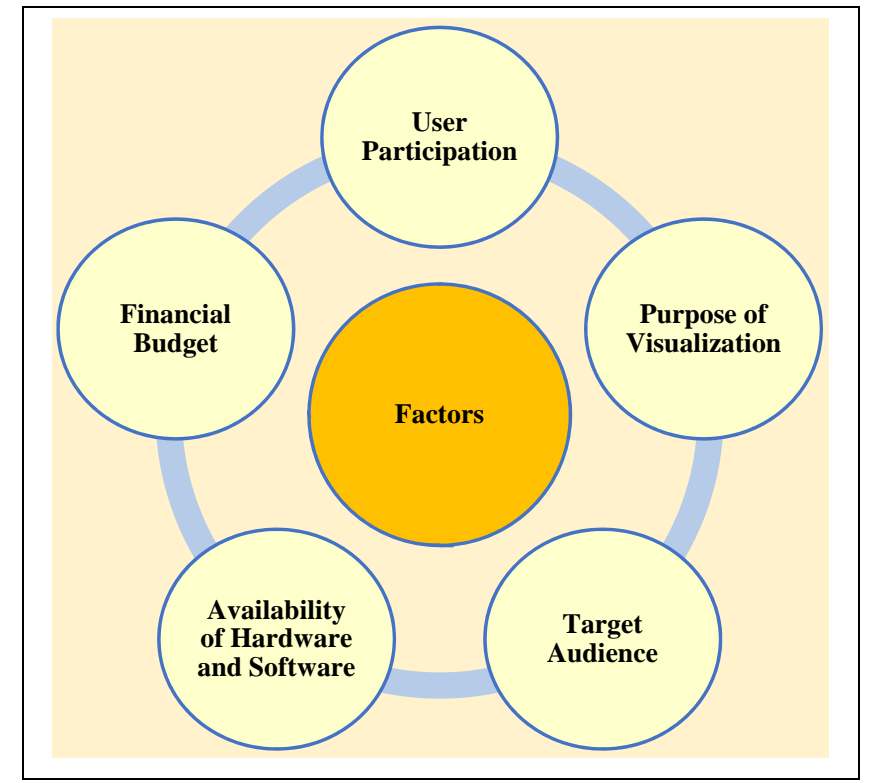

Figure 4. Factors Influencing Selection of Static or Interactive Visualization Approach

\section{KEY PHASES BEFORE AND AFTER VISUALIZATION}

Visualization has a precise sequence of steps being executed by the visualization tools. It involves fundamental steps such as input data, process data and display information graphically. This graphic may have different patterns, colors and sizes. When this output is displayed in the image format, it becomes more understandable and enhancing business decisions.

\section{A. Key Phases in Static Visualization Approach}

The fundamental steps in this process involves selecting the precise data, processing this data and displaying the graphic as an output. [1] This visualization process is executed with the help of visualization software. The process for Static visualization is executed only once since the viewer is not allowed to give further inputs to be executed. Thus, the graphic displayed is meant for only reading purpose. However, the user gets an opportunity to select the type of chart, color schemes, font face, size of font, orientation of the graphic followed by dimensions of the graphic. Selection of the chart and color scheme needs to be done carefully considering various factors such as target audience, purpose of the graphic etc. In order to make the graphic appealing and effective, emphasis should be given on these visual elements. 


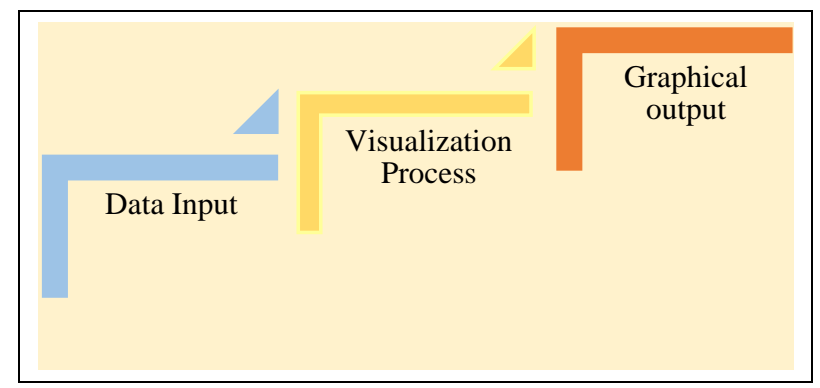

Figure 5. Key Phases in Static Visualization Approach

\section{B. Key Phases in Interactive VisualizationApproach}

The concept of interactive visualization is based on event driven coding. Interactive visualization involves lot of events such as mouse events and keyboard events. [10] This feature makes the application comprehending data easily and quickly. The code for these events is written by the visualization designer at the time of designing the visualization application. However, the user should have the knowledge and training about using this application. The process for Interactive visualization may be a continuous process as the viewer is allowed to give inputs via mouse clicks and keyboard hits. After the input is given, the procedure is repeated and the new graphic is displayed for the user. To use interactive visualization application, precise training is required to the user.

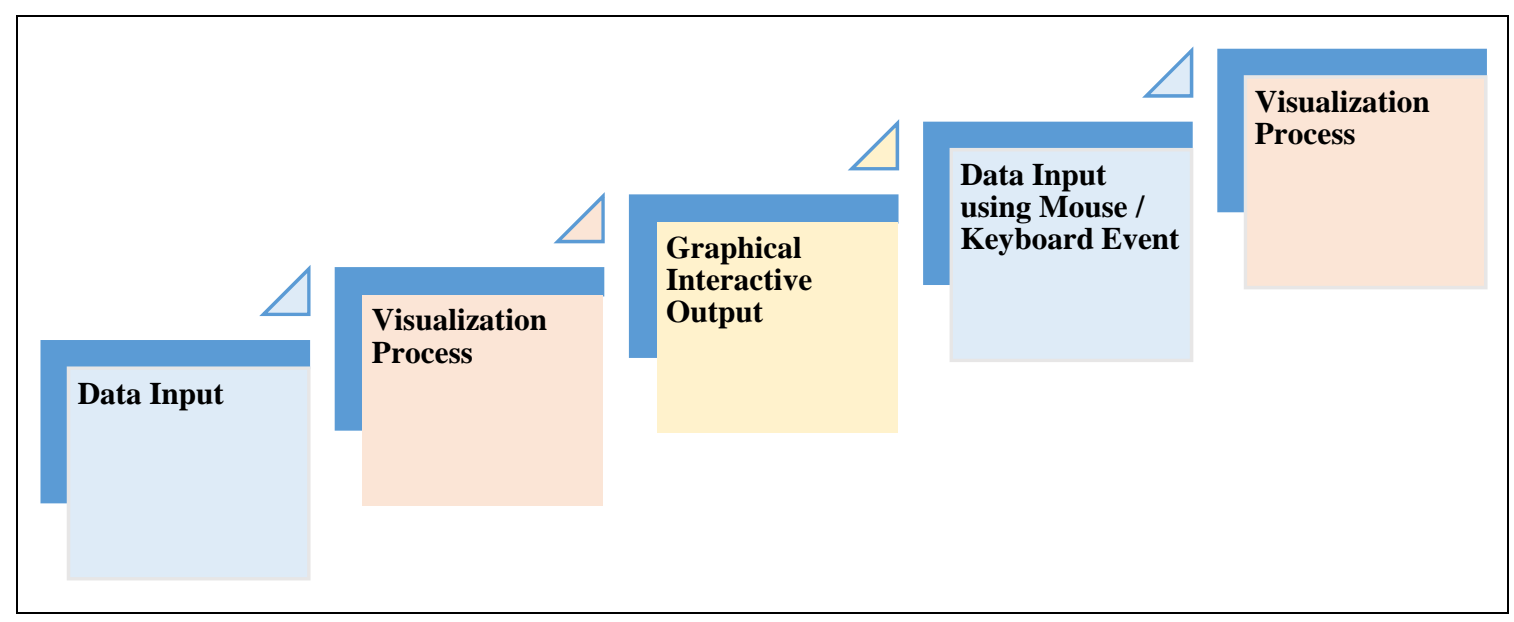

Figure 6. Key Phases in Interactive Visualization Approach

\section{CHALLENGES OF STATIC AND INTERACTIVE VISUALIZATION APPROACHES}

The fundamental challenge for the managers in the organizations is to select the appropriate visualization approach that will fulfill all the visualization requirements. [1]

\section{A. Challenges of Static Visualization Approach}

The key challenge for the author of the static visualization is to provide the complete information at one time as the reader does not get an opportunity to explore the data. The graphic has to cover all the required details. The graphic has to be simple to understand and appealing to the viewers. The graphic should reflect appropriate meaningful information. [1]

\section{B. Challenges of Interactive Visualization Approach}

The key challenge for the author of the interactive visualization is to provide fast access to the data as the reader is giving certain inputs which may be time consuming. Another big challenge for the authors of interactive visualization is to design the user friendly application. It is also essential to train the users with the necessary skills required. [1]

\section{ACKNOWLEDGMENT}

Our sincere thanks to the staff members of our research center, IMED, BharatiVidyapeeth Deemed to be University, Pune, where the review of literature and research work for this paper was being carried out. 


\section{REFERENCES}

[1] Kirti Mahajan and Leena Ajay Gokhale, "Significance of Digital Data Visualization Tools in Big Data Analysis for Business Decisions,” International Journal of Computer Applications (0975 - 8887) Volume 165 - No.5, May 2017.

[2] Kalyani Shirudkar and Dilip Motwani, "Big-Data Security," International Journal of Advanced Research in Computer Science and Software Engineering Volume 5, Issue 3 ISSN: 2277 128X, March 2015.

[3] Peter Krensky, "Interactive Data Visualization Strategies and Key Technologies,” Aberdeen Group, A Harte Hanks Company, March 2014.

[4] "Data Visualization: Making Big Data Approachable and Valuable”, White Paper, SAS.

[5] Sagargouda S.Patil, "Overview of Big Data Visualization," 1st International Conference on Innovations in Computing \& Networking (ICICN16) 12 \& 13, May'16 Organizer: Department of CSE, RRCE 436, May 2016.

[6] Edward Segel and Jeffrey Heer, "Narrative Visualization: Telling Stories with Data”, October 2010.

[7] Robert Kosara and Jock Mackinlay, "Storytelling: The Next Step for Visualization," IEEE Computer Society, 2013.

[8] Chuck Pirrello, "Effective Visualization Techniques for Data Discovery and Analysis,", SAS Institute, Cary, NC, 2010.

[9] T. Alan Keahey, "Using visualization to understand big data", IBM Software, Business Analytics, IBM Corporation Software Group, 2013.

[10] http://www.vbtutor.net/index.php/2013/05/12/visual-basic-6-is-event-driven-programming-language-what-does-it-mean/ 